\title{
Dietary Phytochemicals as Cancer Preventive Agents: Efficacy and Mechanisms
}

\author{
Yohei Shirakami ${ }^{1,2 *}$, Hiroyasu Sakai ${ }^{2}$, Masaya Kubota ${ }^{2}$, Takahiro Kochi² and Masahito Shimizu²
}

${ }^{1}$ Department of Informative Clinical Medicine, Gifu University Graduate School of Medicine, Gifu, Japan

${ }^{2}$ Department of Gastroenterology, Gifu University Graduate School of Medicine, Japan

\begin{abstract}
Despite significant advances in cancer therapeutic modalities, available anti-tumor drugs display limited efficacy and sometimes carry a risk of severe adverse side effect. Therefore, it is important to identify and develop cancer chemopreventive agents without toxicity. Epidemiological examinations in human populations and experimental rodent studies provide evidence that certain types of phytochemicals suppress development and growth of cancers at various organ sites. A number of clinical investigations have been also conducted and shown that dietary phytochemicals are able to inhibit tumorigenesis, indicating several phytochemicals are regarded as cancer chemopreventive agents. Epigallocatechin-3-gallate (EGCG), the major catechin in green tea, is considered as the most biologically active constituent in drinking tea with respect to inhibiting cell proliferation and inducing apoptosis in cancer cells. EGCG appears to directly target receptor tyrosine kinases with inhibiting activation of the receptors and down-stream signaling pathways. In addition, EGCG has improving effects against obesity and insulin resistance, which leads to suppressing the development of obesity-related malignancies. Other polyphenolic phytochemicals, including curcumin and resveratrol, are also reported to exert anti-cancer effect. In this review article, we summarize the potential of dietary phytochemicals as anti-cancer drugs and those possible mechanisms against cancer, especially chemopreventive effect of green tea catechins.
\end{abstract}

Keywords: Capsaicin; Chemoprevention; Chronic inflammation; Colorectal cancer; Curcumin; Genistein; Green tea catechin; Hepatocellular carcinoma; Obesity

\section{Introduction}

A number of epidemiological and experimental investigations have demonstrated an inverse relationship between the risk for some types of cancers and consumption of a diet which has a high content of fruits and vegetables $[1,2]$. These observations indicate that supplementation of nutritional component derived from fruits and vegetables can be useful for cancer prevention. Although these fruits and vegetables have been approved by researchers, especially epidemiologist, the specific components of these plant nutrients and the precise mechanisms of action for cancer prevention have not yet been fully understood. In recent studies, a number of specific phytochemicals, known as plantderived and non-nutritive substances, have been identified which exert anti-cancer effects in various experimental systems [2]. Several mechanisms of action against cancer by these phytochemicals have been implicated, including antioxidant activity, trapping of oxygen radicals, induction of drug metabolizing and detoxifying enzymes, promotion of DNA repair, and modulating tumor-suppressor genes $[3,4]$. In addition to the mechanisms above, recent studies have revealed that several phytochemicals have an anti-cancer effect by regulating activities of various types of receptor tyrosine kinases (RTKs) and their downstream signaling pathways, which are associated with the expression of the genes involved in cell proliferation, angiogenesis, and apoptosis [2,5-8].

Among various types of phytochemicals, (-)-epigallocatechin gallate (EGCG) (Figure 1), the major biologically active component in green tea, appears to be one of the most potent polyphenols regarding inhibition of cell proliferation and induction of apoptosis in cancer cell lines $[5,7,9]$. EGCG have been reported to exert its anti-cancer efficacy by suppressing oxidative stress [9], inhibiting activation of several types of RTKs, regulating epigenetic modification, and modulating immune system $[7,10-16]$. In this review article, we summarize cancer chemopreventive effects of dietary phytochemicals, especially focusing on the mechanisms of EGCG against cancer. This review also mentions other phytochemicals, such as curcumin, capsaicin, and genistein, to possess anti-tumor activity and several clinical studies to examine the possibility of dietary phytochemicals as anti-cancer drugs. Although other phytochemicals, such as resveratrol and anthocyanin, have been reported as cancer preventive agents $[17,18]$, ones from foods taken relatively often in daily life are chosen in this article.

\section{Experimental Studies}

\section{Green tea catechins and EGCG}

Tea is produced from the dried leaves of the tea plant Camellia sinensis and is one of the most widely consumed beverages in the world. It is demonstrated in many epidemiological studies that consumption of tea, especially green tea, is related to decreased incidence of many types of cancers [19]. A number of experimental studies in rodents have also indicated that green tea or its constituents suppress the development and the growth of cancers at various organ sites [9]. Green tea contains several types of catechins, such as EGCG, (-)-epigallocatechin (EGC), (-)-epicatechin-gallate (ECG), and (-)-epicatechin (EC). Among green tea catechins (GTCs), EGCG is considered as one of the major constituents and the most abundant and active constituent in terms

*Corresponding author: Yohei Shirakami, Department of Informative Clinica Medicine and Gastroenterology, Gifu University Graduate School of Medicine, 1-1 Yanagido, Gifu 501-1194, Japan, Tel: +81-58-230-6313; Fax: +81-58-230-6310; E-mail: ys2443@gifu-u.ac.jp

Received March 16, 2015; Accepted April 06, 2015; Published April 10, 2015

Citation: Shirakami Y, Sakai H, Kubota M, Kochi T, Shimizu M (2015) Dietary Phytochemicals as Cancer Preventive Agents: Efficacy and Mechanisms. J Bioanal Biomed 7: 040-049. doi:10.4172/1948-593X.1000122

Copyright: (c) 2015 Shirakami Y, et al. This is an open-access article distributed under the terms of the Creative Commons Attribution License, which permits unrestricted use, distribution, and reproduction in any medium, provided the original author and source are credited. 
<smiles>O=C(OC1Cc2c(O)cc(O)cc2OC1c1cc(O)c(O)c(O)c1)c1cc(O)c(O)c(O)c1</smiles><smiles>O=C1c2c(O)cc(O)cc2OCC1c1ccc(O)cc1</smiles>

Genistein<smiles>COc1cc(/C=C/C(=O)CC(=O)/C=C/c2ccc(O)c(OC)c2)ccc1O</smiles>

Curcumin<smiles>COc1cc(CNC(=O)CCCC/C=C/C(C)C)ccc1O</smiles>

Capsaicin

Figure 1: Chemical structures of representative dietary phytochemicals which have anti-cancer properties.

of inhibiting cell proliferation and inducing apoptosis in cancer cells [20,21]. The chemical structure of EGCG is illustrated in Figure 1. GTCs, especially EGCG, have been extensively examined and reported to have various anti-cancer effects, including induction of apoptosis and cell-cycle arrest, inhibition of NF- $\mathrm{KB}$ and AP-1, suppression of cyclooxygenase- 2 overexpression, modulation of immune system, regulation of epigenetic modification, and inhibition of activation of several types of RTKs [7,9-16]. Some of those anti-cancer mechanisms are shown below.

Apoptosis, known as programmed cell death, is considered to play an important role in the elimination of cancerous cells and to function as an essential protective mechanism against cancer [22]. Previous examinations have indicated that EGCG treatment induces cell-cycle arrest during the G1 phase via regulating expression of cyclin D1, $\mathrm{cdk} 4, \mathrm{p} 21^{\mathrm{CIP} 1}$, and $\mathrm{p} 27^{\mathrm{KIP} 1}$, and induces apoptosis through generation of reactive oxygen species and activation of caspase-3 and -9 [23]. EGCG administration increases the proportion of cells at the G1 phase, decrease cyclin D1 protein levels, and increase $\mathrm{p} 21^{\mathrm{CIP} 1}$, and $\mathrm{p} 27^{\mathrm{KIP} 1}$ proteins levels [12] in head and neck squamous carcinoma (HNSCC) cell lines. In addition, it is reported that treatment with EGCG and other tea polyphenols inhibits cellular growth of PC-9 human lung cancer cells through cell-cycle arrest during the G2/M phase [24]. Another study of the HT29 human colon cancer cell line, treatment with either EGCG alone or combination with other tea catechins was found to increase the number of cells during the G1 phase, induce apoptosis, decrease the levels of cyclin D1 and Bcl-XL protein, and increase caspase-3 and -9 activity [15]. In an in vivo examination of azoxymethan-induced colon carcinogenesis model using obese and diabetic mice, it is demonstrated that administration of EGCG suppresses colon neoplastic lesions and causes a significant decrease in the level of cyclin D1 protein in colonic mucosa [25]. These results suggest that green tea and its constituents, especially EGCG, exert anti-cancer effect by inducing cellular growth arrest and apoptosis through various mechanisms.

Nuclear factor- $\kappa \mathrm{B}(\mathrm{NF}-\kappa \mathrm{B})$ is known as a transcriptional factor and closely associated with cancer development [20]. Masuda et al. [10] demonstrated that EGCG treatment inhibits NF- $\kappa B$ activation in H891 human HNSCC cells and MDA-MB-231 human breast cancer cells. Treatment with EGCG also down-regulates NF- $\mathrm{kB}$ by inducing kinase expression in PC-9 human lung cancer cells [24]. Nuclear translocation of NF- $\kappa \mathrm{B}$ occurs during activation of NF- $\kappa \mathrm{B}$, which leads to suppression of apoptosis and the induction of cellular transformation, proliferation, invasion, metastasis, and inflammation. EGCG treatment is reported to inhibit not only NF- $\kappa B$ activity in human colon cancer cells [20], but also inhibit NF- $\kappa \mathrm{B}$ nuclear translocation in A431 epidermoid carcinoma cells in a dose- and time-dependent manner [26]. Another transcription factor activator protein-1 (AP-1), which regulates gene expressions associated with apoptosis and proliferation, also appears to promote cellular proliferation via up-regulating cyclin D1 and downregulating tumor-suppressor genes, such as p53, p2 $1^{\mathrm{CIP} 1}$, and $\mathrm{p} 16^{\mathrm{INK} 4 \mathrm{a}}$ [20]. EGCG treatment inhibits AP-1 activation and cell transformation in mouse epidermal cell line JB6 [27] and Ras-activated AP-1 activity in the H-ras-transformed JB6 cell line [28]. It is also observed that EGCG treatment inhibits transcriptional activity of AP-1 and NF- $\kappa B$ promoters, as examined by reporter assay [14], and that treatment with either EGCG alone or combination with other tea catechins causes a dose-dependent inhibition of AP-1 luciferase reporter activity in human colon cancer cell line HT29 [15]. These results indicate that GTCs can inhibit both NF- $\mathrm{KB}$ and AP-1 activities, which appear to be a possible mechanism underlying the anti-cancer activity of green tea catechins. 
Cyclooxygenase (COX) is a key regulatory enzyme for prostaglandin synthesis and is divided into two distinct genes, COX-1 and COX-2. While COX-1 is constitutively expressed in whole body, COX-2 expression is controlled by many factors, such as mitogens, tumor promoters, cytokines, and growth factors. In a variety of premalignant and malignant conditions, overexpression of COX-2 has been observed [29]. It is demonstrated that EGCG inhibits mitogenstimulated COX-2 expression in human prostate carcinoma cells [30] and decrease COX-2 expression in human mammary and colon cancer cells $[14,31]$. Our research group has reported that oral administration of GTCs has an inhibitory effect on COX-2 expression in the colon epithelium in a rodent study using inflammation-related colon carcinogenesis model [32]. These observations suggest that GTCs may be a potential candidate for preventing various types of cancers, since development of an agent which inhibits COX-2 expression, preferably without affecting COX-1 expression, can be a promising strategy for cancer chemoprevention [33].

Consumption of green tea has been thought to enhance humoral and cell-mediated immunity, resulting in decreased risk of certain cancers [34]. Immunity is defined as the ability to fight against invading organisms or abnormal conditions in order to prevent the development of various diseases including infection and cancer [35]. Although inflammation is fundamental reaction of immunesystem, inappropriate inflammation frequently becomes a cause of disease. It has been indicated that GTCs have anti-inflammatory efficacy with therapeutic potential, since a number of in vivo studies have shown that administration of green tea polyphenols decreases inflammation. Among those studies, Yang et al. [21] demonstrated that lipopolysaccharide-induced tumor necrosis factor (TNF) production is decreased by administration of green tea polyphenols. Similarly, our research group found that administration of GTCs decreases levels of various inflammatory cytokines, including TNF- $\alpha$, in the colon mucosa and suppresses the development of inflammation-related colon carcinogenesis in a mouse model [32]. Supplementation of green tea and its constituents may have a beneficial effect on inflammatory disorders possibly by exerting anti-inflammatory action via inhibition of NF- $\mathrm{KB}$ activation [36]. Indoleamine 2, 3-dioxygenase (IDO) is a tryptophan catabolic enzyme and is considered to play an important role to induce immune tolerance [37]. Our research group found that EGCG treatment causes a significant decrease in IFN- $\gamma$-induced expression of IDO in human colon cancer cells in a dose-dependent manner [38]. EGCG also significantly inhibits IDO enzymatic activity by suppressing STAT activity [38]. In a rodent study investigating the effects of an IDO inhibitor 1-methyltryptophan (1-MT) and EGCG, it is revealed that both 1-MT and EGCG significantly suppress the development of AOM-induced colonic neoplastic lesions which have overexpression of IDO protein [39]. The study also demonstrates that both 1-MT and EGCG markedly inhibit the increase of IDO activity in the serum and stroma [39]. These findings suggest that EGCG exerts suppressive effect on cancer development presumably through inhibiting both the expression and function of IDO and that EGCG and IDO inhibitor 1-MT are potential anti-tumor agents as immune modulators for cancer chemoprevention.

Epigenetics is the study of the reversible heritable gene expression changes without alteration of DNA sequences. These changes are thought to play a significant role in the regulation of general gene expression and contribute to cancer development due to affecting histone modification and altering chromatin structure [40]. Epigenetic silencing of DNA-repairing and tumor-suppressor genes, which is frequently caused by hyper-methylation and occurs during early stages of carcinogenesis, is associated with various diseases including cancer [41]. Although it has been considered that the effects of EGCG on epigenetic alteration primarily attributes to DNA methylation in cancer cells, a previous study revealed that EGCG also functions as a histone modifier [42]. Treatment with EGCG inhibits the activity of DNA methyltransferase and subsequently induces cytosine-phosphateguanine demethylation and reactivation of silenced tumor-suppressor genes, such as p $16^{\mathrm{INK4a}}$, retinoic acid receptor- $\beta(R A R \beta)$, and O6-methyl guanine-DNA methyltransferase in human esophageal cancer cells [43]. EGCG is also reported to partly promote demethylation of hypermethylated $R A R \beta$ in breast cancer cell lines [40]. Other studies, however, have shown that EGCG treatment exhibits no significant changes in the extent of demethylation or the reactivation of methylation-silenced genes $[44,45]$. In addition, the results from several studies investigating the effects of EGCG on reactivation of silenced genes appear to be still inconclusive [46-48]. Among the studies, Morey et al. has reported that administration of green tea polyphenols neither inhibits prostate tumor progression nor promotes dose dependent alterations in DNA methylation status in a mouse model [47]. Further studies are required to provide evidence that EGCG or GTCs have efficacy on epigenetic alteration as a mechanism against cancer.

Receptor tyrosine kinases (RTKs), which play a pivotal role in cell proliferation and apoptosis, are possible targets of GTCs against cancer $[7,49]$. RTKs and their downstream signaling pathways, including Ras/ extracellular signal-regulated kinase (ERK) and phosphatidylinositol 3-kinase (PI3K)/Akt signaling pathways, regulate the expression of multiple target genes related to cell proliferation and apoptosis [50,51]. Due to binding of growth factors and cytokines as ligands to the extracellular domain of RTKs, it stimulates their tyrosine kinase activity and triggers phosphorylation of specific tyrosine residues [50,51]. The activation of cell-surface RTKs and their multiple downstream signaling play essential roles in various fundamental processes in normal cells. Pre-malignant and malignant cells often display inappropriate activation of RTKs through several mechanisms, such as gene mutation and overexpression [52,53]. The epidermal growth factor receptor (EGFR) family includes four members, namely EGFR (erbB1), HER2 (neu/erbB2), HER3 (neu/erbB3), and HER4 (neu/ erbB4), which belong to subclass I of the RTK superfamily. Insulinlike growth factor-1 receptor (IGF-1R) and vascular endothelial growth factor receptor (VEGFR) belong to other group of RTKs. Although approximately 20 different RTK classes have been identified, abnormalities in certain RTKs, especially EGFR, IGF-1R, and VEGFR2, are deeply associated with the acquisition of malignant properties [5254]. This relationship indicates that EGFR and HER 2 are therapeutic targets in cancer treatment, which is supported by preclinical and clinical evidence in lung and breast cancer [55]. GTCs have been shown to affect several RTKs in a beneficial manner. It is reported that administration of green tea polyphenols in drinking water at a $0.1 \%$ concentration inhibits the development of prostate cancer and metastatic lesions in rodent prostate cancer model [56]. This treatment leads to a decrease of insulin-like growth factor-1 (IGF-1) levels and restoration of IGF binding protein-3 (IGFBP-3) levels, which are associated with reduced levels of PI3K and phosphorylated forms of Akt and ERK [56,57]. In azoxymethan-induced colon carcinogenesis model, similar experimental results were observed in which drinking EGCG induces down-regulated IGF-1 level and suppresses colon premalignant lesions [25]. In in vitro experiment using human colon cancer and hepatoma cells, treatment with EGCG decreases levels of IGF-1 and the activated form of IGF-1R protein, while increasing levels of IGFBP-3, suggesting that EGCG has inhibitory effect on the IGF/ 
IGF-1R axis $[13,16]$. The findings of anti-cancer effects of EGCG on the VEGF/VEGFR axis have been also reported in other studies. EGCG treatment inhibits VEGF production by down-regulating activation of signal transducer and activator of transcription (STAT)-3 and NF- $\kappa B$ in HNSCC and breast cancer cells [10]. In another study, treatment with EGCG inhibits phosphorylation of both VEGFR1 and VEGFR2 and induces apoptosis in B-cell chronic lymphocytic leukemia cells [58]. In addition, it is demonstrated that EGCG suppresses growth of xenografts on mice generated from $\mathrm{HuH} 7$ human hepatoma cells and SW837 human colon cancer cells through suppressing expression of VEGF and activation of VEGFR2, ERK, and Akt $[59,60]$. The effect of GTCs, including EGCG, on ErbB receptor family has been also well investigated and documented. EGCG treatment inhibits not only activation of EGFR and HER2 and their downstream signaling, but also activation of HER3 in various human cancer cell lines [1012,15]. Researchers also found that treatment with EGCG alone or combination with other tea catechins down-regulates the levels of phosphorylated forms of EGFR and HER2, which leads to a decrease in the phosphorylation of ERK and Akt [15].

In addition to the direct effects of EGCG on certain types of RTKs at the cell surface, several studies have revealed that EGCG also has indirect effects on RTKs by targeting the lipid organization in soluble ordered plasma membrane domains known as "lipid rafts". EGCG treatment alters the lipid rafts in human colon cancer cells and inhibits binding of the ligand epidermal growth factor (EGF) to EGFR and the subsequent receptor dimerization [61]. Alterations of lipid organization on the plasma membrane by EGCG induce the internalization of EGFR into endosomes with preventing ligands from binding to EGFR. The degradation of EGFR on cell surface following internalization appears to be induced by phosphorylation of the receptor at serine 1046/1047, which is associated with the activation of $\mathrm{p} 38$ MAPK caused by EGCG [62]. The findings suggest that this novel mechanism may be able to explain ubiquitous effects of EGCG on regulating various types of cell surface RTKs.

Curcumin: Curcumin is a polyphenol (chemical structure in Figure 1) and one of curcuminoids from yellow pigmented turmeric which is a rhizome of the herb Curcuma species. One of the most significant biological effects of curcumin is its anti-inflammatory property. Previous study has reported the property; curcumin is a potent NF$\kappa \mathrm{B}$ inhibitor in human myeloid cells in response to stimulation of tumor necrosis factor (TNF), 12-O-tetradecanoylphobal 13-acetate (TPA), and $\mathrm{H}_{2} \mathrm{O}_{2}$ [63]. Suppressive effect of curcumin on NF- $\kappa B$ activation appears to be due to inhibition of the phosphorylation and subsequent degradation of $\mathrm{I} \kappa \mathrm{B}$, which leads to abrogation of NF- $\kappa \mathrm{B} /$ p65 nuclear translocation [63]. In the study, AP-1 binding factors are also reported to be decreased by curcumin. In addition, curcumin inhibits activation of NF- $\kappa \mathrm{B}$ by down-regulating the upstream kinases caused by phosphorylation of IKB, NIK, and IKK [64]. Numerous studies have reported that curcumin can inhibit NF- $\kappa B$ pathway in various cancer cells, including breast, ovary, prostate, colorectum, and pancreas [65-69]. Curcumin also inhibits the expressions of COX-2 and cyclin D1 [70,71]. Moreover, curcumin has also been identified as an inhibitor of RTKs. Curcumin inhibits EGF-stimulated tyrosine phosphorylation of EGFR [6,70-72] and decreases the activation of down-stream signaling in cell lines [6,70-72]. A recent report has indicated that curcumin exhibits its anti-tumor effect by regulating miRNAs and the expressions of their target genes [73]. Cucumin has been investigated in a number of rodent models of cancer and it is generally accepted that curcumin has a potent cancer chemopreventive function [29,74-76]. Our previous study has revealed that curcumin inhibits chemically induced colonic tumorigenesis [77]. In this study, oral administration of curcumin causes a significant decrease in the number of colonic azoxymethane (AOM)-induced pre-malignant lesions in $\mathrm{C} 57 \mathrm{BL} / \mathrm{KsJ}-\mathrm{db} / \mathrm{db}$ obese and diabetic mice. On the colonic mucosa of the experimental mice, curcumin treatment markedly activates AMP-activated kinase, decreases the expression of proinflammatory cytokines and COX-2, and inhibits NF- $\mathrm{kB}$ activity. Curcumin also increases the levels of adiponectin while decreasing the levels of leptin in serum. These observations in our study suggest that curcumin can attenuate chronic inflammation and ameliorate adipocytokine imbalance, which presumably contribute to suppressing colon carcinogenesis.

Capsaicin: In addition to curcumin, other phytochemicals derived from plants for spices also possess anti-cancer activities. Capsaicin (Figure 1), a pungent constituent of pepper plants, has been widely recognized to have anti-cancer properties with inhibiting proliferation and inducing apoptosis in a large variety of human cancer cell lines [78], while its genotoxic and carcinogenic potential have been also reported in several articles [78-80]. Capsaicin is reported to inhibit TPA-induced $\mathrm{NF}-\kappa \mathrm{B}$ activation through suppressing I $\mathrm{B}$ degradation and subsequent nuclear translocation of NF- $\mathrm{kB} / \mathrm{p} 65$ [81]. It also inhibits TNFa- and TPA-induced binding of AP- 1 and NF- $\mathrm{KB}$ to the binding sites on DNA in human leukemia cells [82] and induces apoptosis by activating JNK1 and p38 and deactivating ERK in human breast epithelial cells [83]. Moreover, vascular endothelial growth factor (VEGF)-stimulated angiogenesis is suppressed by capsaicin treatment due to inhibition of VEGF-induced p38 MAPK and Akt activation [84]. In a rodent study, administration of capsaicin markedly up-regulates phase II enzymes, such as glutathione S-transferase and quinonereductase, in the liver and colon of experimental F344 rats and decreases the development of azoxymethane (AOM)-induced colon pre-malignant lesions, aberrant crypt foci (ACF), and adenocarcinoma [85]. Tanaka et al. [86] have also reported that chemically-induced tongue tumorigenesis is suppressed by supplementation with capsaicin in male F344 rats.

Genistein: Genistein (Figure 1), a soy-derived compound isoflavone, is known as a phytoestrogen which has similar structure of estrogen. This phytochemical has diverse biological activities including cancer chemopreventive function. Its anti-cancer activities have been shown in rodent models as well as in various types of cancer cells through modulation of several signal transduction pathways [87]. Genistein is reported to inhibit TPA-induced c-fos expression, AP-1 activity, and ERK activity in human breast cancer cells [88]. Genistein also reduces $I \kappa B$ phosphorylation and inhibits nuclear translocation of NF- $\kappa B$ leading to decreased DNA binding and NF- $\kappa B$ activation in prostate cancer cells [89]. A recent examination has demonstrated that genistein inhibits cellular proliferation through inactivation of IGF1R/ PI3K/Akt pathway and decrease of the ratio of anti-/pro-apoptotic protein levels in breast cancer cells [90]. In the transgenic mouse model for prostate cancer, supplementation of genistein significantly downregulated activation of EGFR and IGF-1R, both are RTKs, and their downstream signaling [8].

\section{Clinical interventional studies}

Plenty of interventional studies and clinical trials to investigate cancer chemopreventive effects of dietary phytochemicals have been conducted. Among them, we here focus on the investigations of tea catechins, including GTCs and EGCG, and these are introduced and discussed below. The examinations using curcumin and genistein are also well documented and a detailed discussion can be found in 
excellent reviews from Shanmugam et al. [91] and Taylor et al. [92] respectively.

As described above, one potential mechanism underlying the chemopreventive effect of tea is anti-oxidant activity of GTCs. In a phase II randomized interventional trial examining the effect of drinking green tea on reducing DNA damage in heavy smokers, consumption of 4 cups/day of decaffeinated green tea for 4 months significantly decreases in levels of urinary 8-hydroxydeoxyguanosine (8-OHdG), a surrogate biomarker of oxidative DNA damage [93]. Another study, however, has shown no correlation between green tea consumption and lung cancer risk in smokers [94], suggesting that the anti-oxidant activities of green tea play a limited role in decreasing lung cancer risk and, therefore, the existence of an alternative mechanism by which green tea decreases the risk.

Several clinical trials have conducted to examine cancer chemopreventive effects of administrating tea catechins and/or EGCG. Among them, one interventional study has revealed that oral administration of mixed tea products significantly decreases the size of leukoplakia, a pre-malignant lesion in oral mucosa [95]. Another study has found that green tea extracts at a dose of $200 \mathrm{mg}$ for 12 weeks can show therapeutic effect on human papilloma virus-infected cervical lesions which are considered as pre-cancerous lesions [96]. Interestingly, Bettuzzi et al. [97] has reported that oral administration of $600 \mathrm{mg} /$ day of GTCs for 12 months is able to inhibit the progression of pathological lesion from high-grade prostate intraepithelial neoplasia (PIN) to prostate cancer in a randomized, double-blind, placebocontrolled trial. Following-up of the participants as a long-term research revealed that continued inhibition of development of prostate cancer from PIN even two years after initial treatment with GTCs [98]. These observations appear to provide evidence of the beneficial efficacies of GTCs on the prevention of human malignancies, although three other interventional studies investigating the effect of green tea against prostate cancer found no beneficial effects [99-101]. These three studies with negative results include patients with established malignancies of prostate, while only patients with pre-malignant lesions participate in the trial conducted by Bettuzzi et al. $[97,98]$. Therefore, the findings together suggest that treatment with GTCs is probably effective at very early stages of cancer development and that these phytochemicals should be considered as agents for chemoprevention.

Our research group has conducted a pilot study to investigate the effects of treatment with green tea extracts on the development of colorectal adenoma which is considered as a pre-cancerous lesion of the colon [102]. The participants in this trial are patients who had undergone endoscopic polypectomy to remove colorectal adenomas. It is found in the study that oral administration of $1.5 \mathrm{~g} /$ day of green tea extracts for 1 year significantly suppresses the development of colorectal adenomas compared to an untreated control group (Figure 2). The size of relapsed adenomas in the experimental group was

A

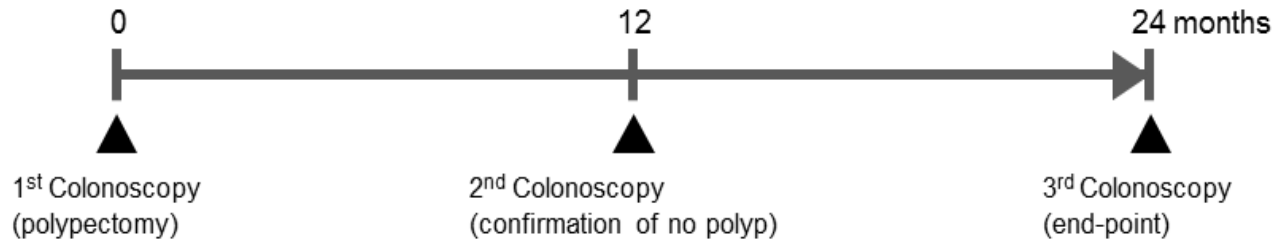

GTE Group Daily Green tea + GTE tablets

Control Group Daily Green tea

B

\begin{tabular}{lccc}
\hline Characteristic & GTE Group & Control Group & $P$ \\
\hline Total no. of patients & 60 & 65 & - \\
No. of patients with metachronous adenomas (\%) & $9(15)$ & $20(31)$ & $<0.05$ \\
Size of relapsed adenomas (mm), mean \pm SD & $3.0 \pm 1.0$ & $4.0 \pm 1.3$ & $<0.001$ \\
\hline
\end{tabular}

Figure 2: A pilot study demonstrating the chemopreventive effect of green tea extract (GTE) on metachronous adenomas after endoscopic polypectomy. (A) Study design. The study included 136 participants who underwent endoscopic resection of one or more colorectal adenomas. Twelve months later, the participants received another total colonoscopy to confirm the absence of remaining endoscopically-detectable adenoma. The participants were then randomized into two groups while administering a daily green tea drinking; the GTE group (71 patients) was given three GTE tablets a day for 12 months and the control group (65 patients) received no supplement. After 12 months of GTE supplementation, a follow-up (end-point) colonoscopy was performed in 125 patients (60 in the GTE group and 65 in the control group) to check the presence of new adenomas. (B) Effects of the GTE supplementation on the incidence and the size of metachronous colorectal adenomas at the end-point colonoscopy. The incidence of adenomas was $15 \%$ (9 of 60$)$ in the GTE group and $31 \%(20$ of 65$)$ in the control group. The size of relapsed adenomas was significantly smaller in the GTE group than that of the control group. 
significantly smaller compared to that of the untreated control group.

A study using GTCs in a high-risk group of individuals for hepatocellular carcinoma (HCC) has been conducted in a region where high exposure aflatoxin which is a risk factor for developing HCC. In this double-blinded and placebo-controlled phase IIa trial, administration of GTCs in these individuals, who are seropositive for both HBs-Ag and aflatoxin-albumin adducts, effectively decreases the levels of urinary 8-hydroxydeoxyguanosine, a surrogate marker of oxidative DNA damage [103]. Daily GTCs consumption also modulated aflatoxin biomarkers in this trial [104]. It is, however, not clear whether GTCs indeed prevent the development of HCC. In addition, HCC development is frequently associated with chronic inflammation and subsequent liver cirrhosis induced by a persistent infection with hepatitis viruses. Recent evidence also indicates that obesity and related metabolic abnormalities, especially insulin resistance, increase the risk for live cancer $[105,106]$, while GTCs appear to exert anti-obesity and anti-diabetic activity $[107,108]$. Therefore, well-designed interventional clinical trials should be conducted to investigate whether GTCs are able to prevent the development of HCC in high-risk patients with viral liver cirrhosis and obesity.

\section{Bioavailability, safety, tolerability, and pharmacokinetics}

Since the bioavailability and plasma concentration are significantly important factors following consumption of phytochemicals, they must be considered when reviewing the findings of in vivo experimental and human clinical studies of the absorption, distribution, and metabolism of dietary phytochemicals [109]. Here, we review previous reports investigating the bioavailability of dietary phytochemicals, focusing on GTCs.

During absorption, polyphenols, including GTCs, are conjugated in the intestine first then in the liver. Methylation, sulfation, and glucuronidation are mainly involved in these reactions [110]. The bioavailability of GTCs in healthy subjects has been examined; consumption of $1.5 \mathrm{mM}$ of EGC, ECG, and EGCG alone have the average plasma levels reach 5.0, 3.1, and $1.3 \mu \mathrm{M}$, respectively [111]. The peak plasma concentrations of EGCG are reached 1-2 $\mathrm{h}$ after oral administration of one dose in fasting state, and then the levels are decreased to undetectable in $24 \mathrm{~h} \mathrm{[112]}$. Therefore, the concentrations of EGCG required to achieve biological effects are much higher in cell culture experiments than the plasma and tissue concentrations detected in experimental animal studies or human trials [113]. In previous in vitro studies, the concentrations of EGCG have ranged from 20 to 100 $\mu \mathrm{M}$, which exceed the concentrations achievable in plasma and tissues by 10 - to 100 -fold [114-117]. Tea catechins actually reach plasma concentrations only in the low micro-molar range following practical tea consumption due to the metabolism in humans [118]. These findings indicate that it remains unclear whether the results obtained from in vitro investigations using much higher levels of EGCG can be directly extrapolated to cancer chemoprevention in animal and human. Nevertheless, it has been considered that the longer duration of exposure and tissue accumulation of these compounds within a living organism may contribute to the effects. In fact, relatively lower levels, approximately $2.2 \mu \mathrm{M}$, of EGCG is sufficient to inhibit growth and induce apoptosis when colon cancer cells are treated for $96 \mathrm{~h}$ rather than $48 \mathrm{~h}$ [15]. Another important in vivo and clinical consideration is that direct contact provided by oral administration appears to lead to much higher levels of GTCs in the epithelia of the digestive tract in comparison with other organs, indicating that GTCs might be even more effective against malignancies in oral and gastrointestinal tissues. This is thought to be common point with other dietary phytochemicals.
The safety of GTCs has been demonstrated in several studies; no adverse events are observed due to administration of tea polyphenols at doses ranging from 600 to $1800 \mathrm{mg} /$ day $[97,102,116,117]$. In order to achieve high levels of tea catechins in serum and tissues, relatively high doses of GTCs are often employed in human interventional studies. Therefore, there have been a growing number of case reports of side effects in humans associated with consuming dietary supplements of green tea, with excess gas, upset stomach, nausea, heartburn, stomachache, abdominal pain, dizziness, headache, muscle pain, and hepatotoxicity, which have been reported with doses ranging from 700 to $2100 \mathrm{mg} /$ day $[117,119]$. These adverse reactions, however, appear to be experienced in studies with supplementation of high doses of GTCs in pills or capsules rather than drinking green tea [120]. A report recently indicates that green tea extracts are able to inhibit certain types of microsomal cytochrome P450 (CYP), but may not contribute to drug-induced liver injury if a drug and green tea are administered simultaneously [121].

It has been revealed that curcumin has poor bioavailability due to its limited solubility in water. A previous study has found that a maximum serum level of $1.35 \pm 0.23 \mu \mathrm{g} / \mathrm{mL}$ is observed at $0.83 \mathrm{~h}$ after oral administration of curcumin $(2 \mathrm{~g} / \mathrm{kg})$ in rats [122]. Other studies show that oral intake of curcumin results in $1 \%$ bioavailability in rat plasma [123,124]. In contrast to rodents, $2 \mathrm{~g} / \mathrm{kg}$, the same dosing in the study in rats above, of curcumin administered orally to humans leads to extremely low concentrations $(0.006 \pm 0.005 \mu \mathrm{g} / \mathrm{mL}$ at $1 \mathrm{~h})$ in serum [122]. In a human clinical trial, the oral dose of $3.6 \mathrm{~g}$ curcumin resulted in plasma concentration of $11.1 \mathrm{nmol} / \mathrm{L}$ at $1 \mathrm{~h}$ after administration [125]. The study has reported that dose-limiting toxicity was not observed in human [125]. The safety of curcumin has also demonstrated in both rats and humans [122].

Capsaicin is also known to have low bioavailability, which is associated with poor water solubility and a short half-life [126,127]. On the other hand, it has been reported that over $90 \%$ of capsaicin can be absorbed rapidly and reach the peak concentration at $1 \mathrm{~h}$ after administration in rats [128]. Another report has shown that capsaicin is detected in serum at $1 \mathrm{~h}$ after oral gavage, while the liver, lungs, and kidney contain the highest concentrations of capsaicin at $2 \mathrm{~h}$ after administration [129]. Among those organs, the lung appears to metabolize capsaicin slower than other organ tissues [129,130], because a higher level of capsaicin can be detected in the lung from $1 \mathrm{~h}$ up to 8 $\mathrm{h}$, while the liver, kidney, or serum contain no capsaicin at $8 \mathrm{~h}$ after oral gavage [129]. The safety of capsaicin has been reported as well as being well-tolerated and no systemic toxicity [131].

A number of pharmacokinetic studies have shown that genistein has poor oral bioavailability and the concentrations in plasma and organ tissues following oral intake are far lower than that in in vitro experiment $[132,133]$, although several clinical trials have demonstrated that genistein has favorable and beneficial effects on chemoprevention against certain types of cancers [92,134]. A previous rodent study has indicate that more than $80 \%$ of genistein is converted to glucuronides and sulfates after both intravenous and oral administrations at $20 \mathrm{mg} /$ $\mathrm{kg}$ and that the absolute bioavailability is $23.4 \%$ [135]. Pharmacokinetic studies have shown that genistein has very long half-life (46 h) after oral administration and that different dose of genistein show no correlation of AUC, suggesting that there may be unknown mechanism of elimination and recycling system $[135,136]$. In human, genistein is extensively metabolized and the plasma level of unconjugated form is very low $[137,138]$. Several human clinical pharmacokinetic studies have revealed that the level of total genistein in plasma is within micro 
molar range while the genistein aglycone, a biological active form compared to genistein conjugates, is in hundred nano molar range $[138,139]$. There were adverse events in a clinical trial using genistein $30 \mathrm{mg} /$ day for 6 weeks, but all events, including gastrointestinal and cardiovascular, were mild and no patients aborted the protocol due to the events [134].

Recently, several formulations of phytochemicals have been prepared in order to enhance bioavailability and to obtain better permeability and resistance to metabolic process. Those include nanoparticles, liposomes, micelles, and phospholipid complex $[127,140,141]$. Nanocurcumin indeed increases bioavailability of curcumin in animals as well as in humans. The pharmacokinetics of the formulation nanoemulsion curcumin have 10 fold increase in the AUC and 40-fold increase in the $\mathrm{C}_{\max }$ compared to curcumin in mice [142]. The colloidal nanoparticles showed more than 40 -fold higher AUC than that of curcumin powder after oral administration in rats. The particles also resulted in 27-fold higher AUC than that of curcumin powder in healthy human volunteers, theracurmin $(30 \mathrm{mg})$ when administered orally [143]. Capsaicin is also able to be encapsulated in liposome, which shows improved oral bioavailability [127].

\section{Concluding Remarks}

Treatment with dietary phytochemicals, including GTCs, appears to offer many potential clinical advantages compared to other traditional anti-cancer agents. Especially, tea catechins can offer the advantages, because it is in globally available beverages, is able to be isolated inexpensively, and is considered as safe agents based on the long history of consuming commonly. As previously discussed, numerous experiments of rodents and human interventional studies have observed no adverse events, even with administration of relatively high doses, although several studies have reported tea catechin-induced toxicity $[116,119]$.

The results of epidemiological studies to examine the effects of green tea consumption on the risk of various human cancers are still inconclusive, although lots of studies of rodent carcinogenesis model have demonstrated significant cancer chemopreventive effects by administration of GTCs. This discrepancy is considered to be attributed to diverse confounding factors, such as variations in human genetics, lifestyle, and etiology of cancer, as well as in the quantity, quality, and type of tea [144]. Among these factors, the amount and type of drinking tea seem to affect the association between tea consumption and cancer risk reduction, because prospective cohort studies have indicated that daily consumption of at least 10 cups of tea, which is equivalent amount of $2.5 \mathrm{~g}$ green tea extract, is required for a cancer chemopreventive effect $[145,146]$. In addition, it is widely accepted that green tea is more effective to decrease a risk for cancer than black tea, possibly because of higher concentrations of tea catechins in green tea [144]. Other confounding factors, such as smoking, alcohol intake, and obesity, may be responsible for the inconsistent results among epidemiological studies to examine the anti-cancer effects of GTCs. For instance, smoking and alcohol intake are known to significantly affect the cancer development in esophagus and liver [147,148].

In order to obtain explicit and conclusive data regarding the chemopreventive effects of GTCs, or other dietary phytochemicals, on malignancies in various organ sites, carefully-conducted cohort studies with a large number of subjects should be performed and designed to remove any potential confounding factors as well.

\section{Acknowledgment}

This work was supported in part by Grants-in-Aid from the Ministry of
Education, Science, Sports and Culture of Japan (No. 25460988 and 50632816 ) Grant-in-Aid for the 3rd Term Comprehensive 10-Year Strategy for Cancer Control from the Ministry of Health, Labor and Welfare of Japan, and the Takeda Science Foundation.

\section{References}

1. Dandona P, Aljada A, Bandyopadhyay A (2004) Inflammation: the link between insulin resistance, obesity and diabetes. Trends Immunol 25: 4-7.

2. Surh YJ1 (2003) Cancer chemoprevention with dietary phytochemicals. Nat Rev Cancer 3: 768-780.

3. Hanausek M, Walaszek Z, Slaga TJ (2003) Detoxifying cancer causing agents to prevent cancer. Integr Cancer Ther 2: 139-144.

4. Hursting SD, Slaga TJ, Fischer SM, DiGiovanni J, Phang JM (1999) Mechanism-based cancer prevention approaches: targets, examples, and the use of transgenic mice. J Natl Cancer Inst 91: 215-225.

5. Khan N, Afaq F, Saleem M, Ahmad N, Mukhtar H (2006) Targeting multiple signaling pathways by green tea polyphenol (-)-epigallocatechin-3-gallate. Cancer Res 66: 2500-2505

6. Korutla L, Cheung JY, Mendelsohn J, Kumar R (1995) Inhibition of ligandinduced activation of epidermal growth factor receptor tyrosine phosphorylation by curcumin. Carcinogenesis 16: 1741-1745.

7. Shimizu M, Weinstein IB (2005) Modulation of signal transduction by tea catechins and related phytochemicals. Mutat Res 591: 147-160.

8. Wang J, Eltoum IE, Lamartiniere CA (2004) Genistein alters growth factor signaling in transgenic prostate model (TRAMP). Mol Cell Endocrinol 219 171-180.

9. Yang CS, Maliakal P, Meng X (2002) Inhibition of carcinogenesis by tea. Annu Rev Pharmacol Toxicol 42: 25-54

10. Masuda M, Suzui M, Lim JT, Deguchi A, Soh JW, et al. (2002) Epigallocatechin3-gallate decreases VEGF production in head and neck and breast carcinoma cells by inhibiting EGFR-related pathways of signal transduction. J Exp Ther Oncol 2: 350-359.

11. Masuda M, Suzui M, Lim JT, Weinstein IB (2003) Epigallocatechin-3-gallate inhibits activation of HER-2/neu and downstream signaling pathways in human head and neck and breast carcinoma cells. Clin Cancer Res 9: 3486-3491.

12. Masuda M, Suzui M, Weinstein IB (2001) Effects of epigallocatechin-3gallate on growth, epidermal growth factor receptor signaling pathways, gene expression, and chemosensitivity in human head and neck squamous cell carcinoma cell lines. Clin Cancer Res 7: 4220-4229.

13. Shimizu M, Deguchi A, Hara Y, Moriwaki H, Weinstein IB (2005) EGCG inhibits activation of the insulin-like growth factor-1 receptor in human colon cancer cells. Biochem Biophys Res Commun 334: 947-953.

14. Shimizu M, Deguchi A, Joe AK, Mckoy JF, Moriwaki H, et al. (2005) EGCG inhibits activation of HER3 and expression of cyclooxygenase-2 in human colon cancer cells. J Exp Ther Oncol 5: 69-78.

15. Shimizu M, Deguchi A, Lim JT, Moriwaki H, Kopelovich L, et al. (2005) (-)-Epigallocatechin gallate and polyphenon $\mathrm{E}$ inhibit growth and activation of the epidermal growth factor receptor and human epidermal growth factor receptor-2 signaling pathways in human colon cancer cells. Clin Cancer Res 11: $2735-2746$.

16. Shimizu M, Shirakami Y, Sakai H, Tatebe H, Nakagawa T, et al. (2008) EGCG inhibits activation of the insulin-like growth factor (IGF)/IGF-1 receptor axis in human hepatocellular carcinoma cells. Cancer Lett 262: 10-18.

17. Singh M, Suman S, Shukla Y (2014) New Enlightenment of Skin Cancer Chemoprevention through Phytochemicals: In Vitro and In Vivo Studies and the Underlying Mechanisms. Biomed Res Int 2014: 243452.

18. Kaur P, Shorey LE, Ho E, Dashwood RH, Williams DE (2013) The epigenome as a potential mediator of cancer and disease prevention in prenatal development. Nutr Rev 71: 441-457.

19. Yang CS, Wang ZY (1993) Tea and cancer. J Natl Cancer Inst 85: 1038-1049.

20. Ahmad N, Feyes DK, Nieminen AL, Agarwal R, Mukhtar H (1997) Green tea constituent epigallocatechin-3-gallate and induction of apoptosis and cell cycle arrest in human carcinoma cells. J Natl Cancer Inst 89: 1881-1886.

21. Yang GY, Liao J, Kim K, Yurkow EJ, Yang CS (1998) Inhibition of growth 
and induction of apoptosis in human cancer cell lines by tea polyphenols. Carcinogenesis 19: 611-616.

22. Shankar S, Ganapathy S, Hingorani SR, Srivastava RK (2008) EGCG inhibits growth, invasion, angiogenesis and metastasis of pancreatic cancer. Front Biosci 13: 440-452.

23. Shankar S, Suthakar G, Srivastava RK (2007) Epigallocatechin-3-gallate inhibits cell cycle and induces apoptosis in pancreatic cancer. Front Biosci 12: 5039-5051.

24. Fujiki H, Suganuma M, Okabe S, Sueoka N, Komori A, et al. (1998) Cancer inhibition by green tea. Mutat Res 402: 307-310.

25. Shimizu M, Shirakami Y, Sakai H, Adachi S, Hata K, et al. (2008) (-)-Epigallocatechin gallate suppresses azoxymethane-induced colonic premalignant lesions in male C57BL/KsJ-db/db mice. Cancer Prev Res (Phila) 1: 298-304.

26. Gupta S, Hastak K, Afaq F, Ahmad N, Mukhtar H (2004) Essential role of caspases in epigallocatechin-3-gallate-mediated inhibition of nuclear factor kappa B and induction of apoptosis. Oncogene 23: 2507-2522.

27. Dong Z, Ma W, Huang C, Yang CS (1997) Inhibition of tumor promoter-induced activator protein 1 activation and cell transformation by tea polyphenols, (-)-epigallocatechin gallate, and theaflavins. Cancer Res 57: 4414-4419.

28. Chung JY, Huang C, Meng X, Dong Z, Yang CS (1999) Inhibition of activator protein 1 activity and cell growth by purified green tea and black tea polyphenols in H-ras-transformed cells: structure-activity relationship and mechanisms involved. Cancer Res 59: 4610-4617.

29. Aggarwal BB, Kumar A, Bharti AC (2003) Anticancer potential of curcumin: preclinical and clinical studies. Anticancer Res 23: 363-398.

30. Hussain T, Gupta S, Adhami VM, Mukhtar H (2005) Green tea constituent epigallocatechin-3-gallate selectively inhibits COX-2 without affecting COX-1 expression in human prostate carcinoma cells. Int J Cancer 113: 660-669.

31. Kundu JK, Na HK, Chun KS, Kim YK, Lee SJ, et al. (2003) Inhibition of phorbol ester-induced COX-2 expression by epigallocatechin gallate in mouse skin and cultured human mammary epithelial cells. J Nutr 133: 3805S-3810S

32. Shirakami Y, Shimizu M, Tsurumi H, Hara Y, Tanaka T, et al. (2008) EGCG and Polyphenon $E$ attenuate inflammation-related mouse colon carcinogenesis induced by AOM plus DDS. Mol Med Rep 1: 355-361.

33. Moreira L, Castells A (2011) Cyclooxygenase as a target for colorectal cancer chemoprevention. Curr Drug Targets 12: 1888-1894.

34. Klein C, Sato T, Meguid MM, Miyata G (2000) From food to nutritional support to specific nutraceuticals: a journey across time in the treatment of disease. J Gastroenterol 35 Suppl 12: 1-6.

35. Little TJ, Hultmark D, Read AF (2005) Invertebrate immunity and the limits of mechanistic immunology. Nat Immunol 6: 651-654.

36. Butt MS, Sultan MT (2009) Green tea: nature's defense against malignancies. Crit Rev Food Sci Nutr 49: 463-473.

37. Uyttenhove C, Pilotte L, Théate I, Stroobant V, Colau D, et al. (2003) Evidence for a tumoral immune resistance mechanism based on tryptophan degradation by indoleamine 2,3-dioxygenase. Nat Med 9: 1269-1274

38. Ogawa K, Hara T, Shimizu M, Nagano J, Ohno T, et al. (2012)(-)-Epigallocatechin gallate inhibits the expression of indoleamine 2,3-dioxygenase in human colorectal cancer cells. Oncol Lett 4: 546-550.

39. Ogawa K, Hara T, Shimizu M, Ninomiya S, Nagano J, et al. (2012) Suppression of azoxymethane-induced colonic preneoplastic lesions in rats by 1-methyltryptophan, an inhibitor of indoleamine 2,3-dioxygenase. Cancer Sci 103: 951-958.

40. Link A, Balaguer F, Goel A (2010) Cancer chemoprevention by dietary polyphenols: promising role for epigenetics. Biochem Pharmacol 80: 17711792.

41. Feinberg AP, Tycko B (2004) The history of cancer epigenetics. Nat Rev Cancer 4: 143-153.

42. Choi KC, Jung MG, Lee YH, Yoon JC, Kwon SH, et al. (2009) Epigallocatechin3-gallate, a histone acetyltransferase inhibitor, inhibits EBV-induced B lymphocyte transformation via suppression of RelA acetylation. Cancer Res 69: 583-592.
43. Fang M, Chen D, Yang CS (2007) Dietary polyphenols may affect DNA methylation. J Nutr 137: 223S-228S.

44. Chuang JC, Yoo CB, Kwan JM, Li TW, Liang G, et al. (2005) Comparison of biological effects of non-nucleoside DNA methylation inhibitors versus 5-aza2'-deoxycytidine. Mol Cancer Ther 4: 1515-1520.

45. Stresemann C, Brueckner B, Musch T, Stopper H, Lyko F (2006) Functional diversity of DNA methyltransferase inhibitors in human cancer cell lines. Cancer Res 66: 2794-2800.

46. Mittal A, Piyathilake C, Hara Y, Katiyar SK (2003) Exceptionally high protection of photocarcinogenesis by topical application of (--)-epigallocatechin-3-gallate in hydrophilic cream in SKH-1 hairless mouse model: relationship to inhibition of UVB-induced global DNA hypomethylation. Neoplasia 5: 555-565.

47. Morey Kinney SR, Zhang W, Pascual M, Greally JM, Gillard BM, et al. (2009) Lack of evidence for green tea polyphenols as DNA methylation inhibitors in murine prostate. Cancer Prev Res (Phila) 2: 1065-1075

48. Tsao AS, Liu D, Martin J, Tang XM, Lee JJ, et al. (2009) Phase II randomized placebo-controlled trial of green tea extract in patients with high-risk ora premalignant lesions. Cancer Prev Res (Phila) 2: 931-941.

49. Shimizu M, Shirakami $Y$, Moriwaki $H$ (2008) Targeting receptor tyrosine kinases for chemoprevention by green tea catechin, EGCG. Int J Mol Sci 9: 1034-1049.

50. Lemmon MA, Schlessinger J (2010) Cell signaling by receptor tyrosine kinases Cell 141: 1117-1134

51. Schlessinger J (2000) Cell signaling by receptor tyrosine kinases. Cell 103 211-225.

52. Hynes NE, Lane HA (2005) ERBB receptors and cancer: the complexity of targeted inhibitors. Nat Rev Cancer 5: 341-354.

53. Pollak MN, Schernhammer ES, Hankinson SE (2004) Insulin-like growth factors and neoplasia. Nat Rev Cancer 4: 505-518.

54. Ellis LM, Hicklin DJ (2008) VEGF-targeted therapy: mechanisms of anti-tumour activity. Nat Rev Cancer 8: 579-591.

55. Press MF, Lenz HJ (2007) EGFR, HER2 and VEGF pathways: validated targets for cancer treatment. Drugs 67: 2045-2075.

56. Gupta RA, Dubois RN (2001) Colorectal cancer prevention and treatment by inhibition of cyclooxygenase-2. Nat Rev Cancer 1: 11-21.

57. Adhami VM, Siddiqui IA, Ahmad N, Gupta S, Mukhtar H (2004) Oral consumption of green tea polyphenols inhibits insulin-like growth factor-l-induced signaling in an autochthonous mouse model of prostate cancer. Cancer Res 64: 87158722.

58. Lee YK, Bone ND, Strege AK, Shanafelt TD, Jelinek DF, et al. (2004) VEGF receptor phosphorylation status and apoptosis is modulated by a green tea component, epigallocatechin-3-gallate (EGCG), in B-cell chronic lymphocytic leukemia. Blood 104: 788-794.

59. Shimizu M, Shirakami Y, Sakai H, Yasuda Y, Kubota M, et al. (2010) (-)-Epigallocatechin gallate inhibits growth and activation of the VEGF/VEGFR axis in human colorectal cancer cells. Chem Biol Interact 185: 247-252.

60. Shirakami Y, Shimizu M, Adachi S, Sakai H, Nakagawa T, et al. (2009) (-)-Epigallocatechin gallate suppresses the growth of human hepatocellular carcinoma cells by inhibiting activation of the vascular endothelial growth factorvascular endothelial growth factor receptor axis. Cancer Sci 100: 1957-1962.

61. Adachi S, Nagao T, Ingolfsson HI, Maxfield FR, Andersen OS, et al. (2007) The inhibitory effect of (-)-epigallocatechin gallate on activation of the epidermal growth factor receptor is associated with altered lipid order in HT29 colon cancer cells. Cancer Res 67: 6493-6501.

62. Adachi S, Shimizu M, Shirakami Y, Yamauchi J, Natsume H, et al. (2009) (-)-Epigallocatechin gallate downregulates EGF receptor via phosphorylation at Ser1046/1047 by p38 MAPK in colon cancer cells. Carcinogenesis 30: 15441552.

63. Singh S, Aggarwal BB (1995) Activation of transcription factor NF-kappa B is suppressed by curcumin (diferuloylmethane) [corrected]. J Biol Chem 270 : 24995-25000.

64. Plummer SM, Holloway KA, Manson MM, Munks RJ, Kaptein A, et al. (1999) Inhibition of cyclo-oxygenase 2 expression in colon cells by the chemopreventive agent curcumin involves inhibition of NF-kappaB activation via the NIK/IKK signalling complex. Oncogene 18: 6013-6020. 
65. Chen SS, Michael A, Butler-Manuel SA (2012) Advances in the treatment of ovarian cancer: a potential role of antiinflammatory phytochemicals. Discov Med 13: 7-17.

66. Jutooru I, Chadalapaka G, Lei P, Safe S (2010) Inhibition of NFkappaB and pancreatic cancer cell and tumor growth by curcumin is dependent on specificity protein down-regulation. J Biol Chem 285: 25332-25344.

67. Killian PH, Kronski E, Michalik KM, Barbieri O, Astigiano S, et al. (2012) Curcumin inhibits prostate cancer metastasis in vivo by targeting the inflammatory cytokines CXCL1 and -2. Carcinogenesis 33: 2507-2519.

68. Sandur SK, Deorukhkar A, Pandey MK, Pabón AM, Shentu S, et al. (2009) Curcumin modulates the radiosensitivity of colorectal cancer cells by suppressing constitutive and inducible NF-kappaB activity. Int J Radiat Oncol Biol Phys 75: 534-542.

69. Yodkeeree S, Ampasavate C, Sung B, Aggarwal BB, Limtrakul P (2010) Demethoxycurcumin suppresses migration and invasion of MDA-MB-231 human breast cancer cell line. Eur J Pharmacol 627: 8-15.

70. Huang T, Chen Z, Fang L (2013) Curcumin inhibits LPS-induced EMT through downregulation of NF-1̂ं B-Snail signaling in breast cancer cells. Oncol Rep 29: 117-124

71. Royt M, Mukherjee S, Sarkar R, Biswas J (2011) Curcumin sensitizes chemotherapeutic drugs via modulation of PKC, telomerase, NF-kappaB and HDAC in breast cancer. Ther Deliv 2: 1275-1293.

72. Squires MS, Hudson EA, Howells L, Sale S, Houghton CE, et al. (2003) Relevance of mitogen activated protein kinase (MAPK) and phosphotidylinositol3-kinase/protein kinase B (PI3K/PKB) pathways to induction of apoptosis by curcumin in breast cells. Biochem Pharmacol 65: 361-376.

73. Toden S, Okugawa Y, Buhrmann C, Nattamai D, Anguiano E, et al. (2015) Novel evidence for curcumin and boswellic acid induced chemoprevention through regulation of miR-34a and miR-27a in colorectal cancer. Cancer Prev Res (Phila).

74. Bachmeier BE, Killian P, Pfeffer U, Nerlich AG (2010) Novel aspects for the application of Curcumin in chemoprevention of various cancers. Front Biosci (Schol Ed) 2: 697-717.

75. Bar-Sela G, Epelbaum R, Schaffer M (2010) Curcumin as an anti-cancer agent: review of the gap between basic and clinical applications. Curr Med Chem 17: 190-197.

76. Hossain DM, Bhattacharyya S, Das T, Sa G (2012) Curcumin: the multitargeted therapy for cancer regression. Front Biosci (Schol Ed) 4: 335-355.

77. Kubota M, Shimizu M, Sakai H, Yasuda Y, Terakura D, et al. (2012) Preventive effects of curcumin on the development of azoxymethane-induced colonic preneoplastic lesions in male C57BL/KsJ-db/db obese mice. Nutr Cancer 64: $72-79$

78. Oyagbemi AA, Saba AB, Azeez OI (2010) Capsaicin: a novel chemopreventive molecule and its underlying molecular mechanisms of action. Indian $\mathrm{J}$ Cancer 47: 53-58

79. Lawson T, Gannett $P$ (1989) The mutagenicity of capsaicin and dihydrocapsaicin in V79 cells. Cancer Lett 48: 109-113.

80. Marques S, Oliveira NG, Chaveca T, Rueff J (2002) Micronuclei and sister chromatid exchanges induced by capsaicin in human lymphocytes. Mutat Res 517: 39-46.

81. Han SS, Keum YS, Seo HJ, Chun KS, Lee SS, et al. (2001) Capsaicin suppresses phorbol ester-induced activation of NF-kappaB/Rel and AP-1 transcription factors in mouse epidermis. Cancer Lett 164: 119-126.

82. Duvoix A, Delhalle S, Blasius R, Schnekenburger M, Morceau F, et al. (2004) Effect of chemopreventive agents on glutathione S-transferase P1-1 gene expression mechanisms via activating protein 1 and nuclear factor kappaB inhibition. Biochem Pharmacol 68: 1101-1111.

83. Kang HJ, Soh Y, Kim MS, Lee EJ, Surh YJ, et al. (2003) Roles of JNK-1 and p38 in selective induction of apoptosis by capsaicin in ras-transformed human breast epithelial cells. Int J Cancer 103: 475-482.

84. Min JK, Han KY, Kim EC, Kim YM, Lee SW, et al. (2004) Capsaicin inhibits in vitro and in vivo angiogenesis. Cancer Res 64: 644-651.

85. Yoshitani SI, Tanaka T, Kohno H, Takashima S (2001) Chemoprevention of azoxymethane-induced rat colon carcinogenesis by dietary capsaicin and rotenone. Int J Oncol 19: 929-939.
86. Tanaka T, Kohno H, Sakata K, Yamada Y, Hirose Y, et al. (2002) Modifying effects of dietary capsaicin and rotenone on 4-nitroquinoline 1-oxide-induced rat tongue carcinogenesis. Carcinogenesis 23: 1361-1367.

87. Sarkar FH, Li Y (2003) Soy isoflavones and cancer prevention. Cancer Invest 21: 744-757

88. Dampier K, Hudson EA, Howells LM, Manson MM, Walker RA, et al. (2001) Differences between human breast cell lines in susceptibility towards growth inhibition by genistein. $\mathrm{Br} \mathrm{J}$ Cancer 85 : 618-624.

89. Davis JN, Kucuk O, Sarkar FH (1999) Genistein inhibits NF-kappa B activation in prostate cancer cells. Nutr Cancer 35: 167-174.

90. Chen J, Duan Y, Zhang X, Ye Y, Ge B, et al. (2015) Genistein induces apoptosis by the inactivation of the IGF-1R/p-Akt signaling pathway in MCF-7 human breast cancer cells. Food Funct 6: 995-1000.

91. Shanmugam MK, Rane G, Kanchi MM, Arfuso F, et al. (2015) The multifaceted role of curcumin in cancer prevention and treatment. Molecules 20: 2728-2769.

92. Taylor CK, Levy RM, Elliott JC, Burnett BP (2009) The effect of genistein aglycone on cancer and cancer risk: a review of in vitro, preclinical, and clinical studies. Nutr Rev 67: 398-415.

93. Hakim IA, Harris RB, Brown S, Chow HH, Wiseman S, et al. (2003) Effect of increased tea consumption on oxidative DNA damage among smokers: a randomized controlled study. J Nutr 133: 3303S-3309S.

94. Zhong L, Goldberg MS, Gao YT, Hanley JA, Parent ME, et al. (2001) A population-based case-control study of lung cancer and green tea consumption among women living in Shanghai, China. Epidemiology 12: 695-700.

95. Li N, Sun Z, Han C, Chen J (1999) The chemopreventive effects of tea on human oral precancerous mucosa lesions. Proc Soc Exp Biol Med 220: 218-224.

96. Ahn WS, Yoo J, Huh SW, Kim CK, Lee JM, et al. (2003) Protective effects of green tea extracts (polyphenon E and EGCG) on human cervical lesions. Eur J Cancer Prev 12: 383-390.

97. Bettuzzi S, Brausi M, Rizzi F, Castagnetti G, Peracchia G, et al. (2006) Chemoprevention of human prostate cancer by oral administration of green tea catechins in volunteers with high-grade prostate intraepithelial neoplasia: a preliminary report from a one-year proof-of-principle study. Cancer Res 66 : 1234-1240.

98. Brausi M, Rizzi F, Bettuzzi S (2008) Chemoprevention of human prostate cancer by green tea catechins: two years later. A follow-up update. Eur Urol 54: $472-473$

99. Choan E, Segal R, Jonker D, Malone S, Reaume N, et al. (2005) A prospective clinical trial of green tea for hormone refractory prostate cancer: an evaluation of the complementary/alternative therapy approach. Urol Oncol 23: 108-113.

100. Jatoi A, Ellison N, Burch PA, Sloan JA, Dakhil SR, et al. (2003) A phase II trial of green tea in the treatment of patients with androgen independent metastatic prostate carcinoma. Cancer 97: 1442-1446.

101. McLarty J, Bigelow RL, Smith M, Elmajian D, Ankem M, et al. (2009) Tea polyphenols decrease serum levels of prostate-specific antigen, hepatocyte growth factor, and vascular endothelial growth factor in prostate cancer patients and inhibit production of hepatocyte growth factor and vascular endothelial growth factor in vitro. Cancer Prev Res (Phila) 2: 673-682.

102. Shimizu M, Fukutomi Y, Ninomiya M, Nagura K, Kato T, et al. (2008) Green tea extracts for the prevention of metachronous colorectal adenomas: a pilot study. Cancer Epidemiol Biomarkers Prev 17: 3020-3025.

103. Luo H, Tang L, Tang M, Billam M, Huang T, et al. (2006) Phase Ila chemoprevention trial of green tea polyphenols in high-risk individuals of liver cancer: modulation of urinary excretion of green tea polyphenols and 8-hydroxydeoxyguanosine. Carcinogenesis 27: 262-268.

104. Tang L, Tang M, Xu L, Luo H, Huang T, et al. (2008) Modulation of aflatoxin biomarkers in human blood and urine by green tea polyphenols intervention. Carcinogenesis 29: 411-417.

105. El-Serag HB, Rudolph KL (2007) Hepatocellular carcinoma: epidemiology and molecular carcinogenesis. Gastroenterology 132: 2557-2576.

106. Muto Y, Sato S, Watanabe A, Moriwaki H, Suzuki K, et al. (2006) Overweigh and obesity increase the risk for liver cancer in patients with liver cirrhosis and long-term oral supplementation with branched-chain amino acid granules inhibits liver carcinogenesis in heavier patients with liver cirrhosis. Hepatol Res 35: 204-214. 
107. Kao YH, Chang HH, Lee MJ, Chen CL (2006) Tea, obesity, and diabetes. Mol Nutr Food Res 50: 188-210.

108. Shimizu M, Sakai H, Shirakami Y, Yasuda Y, Kubota M, et al. (2011) Preventive effects of (-)-epigallocatechin gallate on diethylnitrosamine-induced live tumorigenesis in obese and diabetic C57BL/KsJ-db/db Mice. Cancer Prev Res (Phila) 4: 396-403.

109. Lee MJ, Wang ZY, Li H, Chen L, Sun Y, et al. (1995) Analysis of plasma and urinary tea polyphenols in human subjects. Cancer Epidemiol Biomarkers Prev 4: 393-399.

110. Mereles D, Hunstein W (2011) Epigallocatechin-3-gallate (EGCG) for clinical trials: more pitfalls than promises? Int J Mol Sci 12: 5592-5603.

111. van het Hof KH, Kivits GA, Weststrate JA, Tijburg LB (1998) Bioavailability of catechins from tea: the effect of milk. Eur J Clin Nutr 52: 356-359.

112. Lee MJ, Maliakal P, Chen L, Meng X, Bondoc FY, et al. (2002) Pharmacokinetics of tea catechins after ingestion of green tea and (-)-epigallocatechin-3-gallate by humans: formation of different metabolites and individual variability. Cancer Epidemiol Biomarkers Prev 11: 1025-1032.

113. Yang F, de Villiers WJ, McClain CJ, Varilek GW (1998) Green tea polyphenols block endotoxin-induced tumor necrosis factor-production and lethality in a murine model. J Nutr 128: 2334-2340.

114. Ju J, Lu G, Lambert JD, Yang CS (2007) Inhibition of carcinogenesis by tea constituents. Semin Cancer Biol 17: 395-402.

115. Yang CS, Wang $X(2010)$ Green tea and cancer prevention. Nutr Cancer 62: 931-937.

116. Chow HH, Cai Y, Alberts DS, Hakim I, Dorr R, et al. (2001) Phase I pharmacokinetic study of tea polyphenols following single-dose administration of epigallocatechin gallate and polyphenon E. Cancer Epidemiol Biomarkers Prev 10: 53-58.

117. Chow HH, Cai Y, Hakim IA, Crowell JA, Shahi F, et al. (2003) Pharmacokinetics and safety of green tea polyphenols after multiple-dose administration of epigallocatechin gallate and polyphenon $\mathrm{E}$ in healthy individuals. Clin Cancer Res 9: 3312-3319.

118. Yang CS, Sang S, Lambert JD, Lee MJ (2008) Bioavailability issues in studying the health effects of plant polyphenolic compounds. Mol Nutr Food Res 52 Suppl 1: S139-151.

119. Mazzanti G, Menniti-Ippolito F, Moro PA, Cassetti F, Raschetti R, et al. (2009) Hepatotoxicity from green tea: a review of the literature and two unpublished cases. Eur J Clin Pharmacol 65: 331-341.

120. Jimenez-Saenz M, Martinez-Sanchez Mdel C (2006) Acute hepatitis associated with the use of green tea infusions. J Hepatol 44: 616-617.

121. Teschke R, Zhang L, Melzer L, Schulze J, Eickhoff A (2014) Green tea extract and the risk of drug-induced liver injury. Expert Opin Drug Metab Toxicol 10: 1663-1676.

122. Shoba G, Joy D, Joseph T, Majeed M, Rajendran R, et al. (1998) Influence of piperine on the pharmacokinetics of curcumin in animals and human volunteers. Planta Med 64: 353-356.

123. Yang KY, Lin LC, Tseng TY, Wang SC, Tsai TH (2007) Oral bioavailability of curcumin in rat and the herbal analysis from Curcuma longa by LC-MS/MS. J Chromatogr B Analyt Technol Biomed Life Sci 853: 183-189.

124.Chang MT, Tsai TR, Lee CY, Wei YS, Chen YJ, et al. (2013) Elevating bioavailability of curcumin via encapsulation with a novel formulation of artificial oil bodies. J Agric Food Chem 61: 9666-9671.

125. Sharma RA, Euden SA, Platton SL, Cooke DN, Shafayat A, et al. (2004) Phase I clinical trial of oral curcumin: biomarkers of systemic activity and compliance. Clin Cancer Res 10: 6847-6854.

126. Kawada T, Watanabe T, Katsura K, Takami H, Iwai K (1985) Formation and metabolism of pungent principle of Capsicum fruits. XV. Microdetermination of capsaicin by high-performance liquid chromatography with electrochemical detection. J Chromatogr 329: 99-105.

127.Zhu Y, Wang M, Zhang J, Peng W, Firempong CK, et al. (2015) Improved oral bioavailability of capsaicin via liposomal nanoformulation: preparation, in vitro drug release and pharmacokinetics in rats. Arch Pharm Res 38: 512-521.

128. Suresh D, Srinivasan K (2010) Tissue distribution \& elimination of capsaicin, piperine \& curcumin following oral intake in rats. Indian J Med Res 131: 682-691.
129. Rollyson WD, Stover CA, Brown KC, Perry HE, Stevenson CD, et al. (2014) Bioavailability of capsaicin and its implications for drug delivery. J Control Release 196: 96-105.

130. Reilly CA, Ehlhardt WJ, Jackson DA, Kulanthaivel P, Mutlib AE, et al. (2003) Metabolism of capsaicin by cytochrome $\mathrm{P} 450$ produces novel dehydrogenated metabolites and decreases cytotoxicity to lung and liver cells. Chem Res Toxicol 16: 336-349.

131.Laslett LL, Jones G (2014) Capsaicin for osteoarthritis pain. Prog Drug Res 68: 277-291.

132. Setchell KD, Brown NM, Desai P, Zimmer-Nechemias L, Wolfe BE, et al (2001) Bioavailability of pure isoflavones in healthy humans and analysis of commercial soy isoflavone supplements. J Nutr 131: 1362S-75S.

133. Kano M, Takayanagi T, Harada K, Sawada S, Ishikawa F (2006) Bioavailability of isoflavones after ingestion of soy beverages in healthy adults. J Nutr 136 2291-2296.

134. Lazarevic B, Boezelijn G, Diep LM, Kvernrod K, Ogren O, et al. (2011) Efficacy and safety of short-term genistein intervention in patients with localized prostate cancer prior to radical prostatectomy: a randomized, place bo-controlled, double-blind Phase 2 clinical trial. Nutr Cancer 63: 889-898.

135. Yang Z, Zhu W, Gao S, Xu H, Wu B, et al. (2010) Simultaneous determination of genistein and its four phase II metabolites in blood by a sensitive and robust UPLC-MS/MS method: Application to an oral bioavailability study of genistein in mice. J Pharm Biomed Anal 53: 81-89.

136. Zhou S, Hu Y, Zhang B, Teng Z, Gan H, et al. (2008) Dose-dependent absorption, metabolism, and excretion of genistein in rats. J Agric Food Chem 56: 8354-8359.

137. Hosoda K, Furuta T, Yokokawa A, Ishii K (2010) Identification and quantification of daidzein-7-glucuronide-4'-sulfate, genistein-7-glucuronide-4'-sulfate and genistein-4',7-diglucuronide as major metabolites in human plasma after administration of kinako. Anal Bioanal Chem 397: 1563-1572.

138. Fischer L, Mahoney C, Jeffcoat AR, Koch MA, Thomas BE, et al. (2004) Clinical characteristics and pharmacokinetics of purified soy isoflavones: multiple-dose administration to men with prostate neoplasia. Nutr Cancer 48 : 160-170.

139. Yang Z, Kulkarni K, Zhu W, Hu M (2012) Bioavailability and pharmacokinetics of genistein: mechanistic studies on its ADME. Anticancer Agents Med Chem 12: $1264-1280$

140.Prasad S, Tyagi AK, Aggarwal BB (2014) Recent developments in delivery, bioavailability, absorption and metabolism of curcumin: the golden pigment from golden spice. Cancer Res Treat 46: 2-18.

141.Desai PR, Marepally S, Patel AR, Voshavar C, Chaudhuri A, et al. (2013) Topical delivery of anti-TNFalpha siRNA and capsaicin via novel lipid-polymer hybrid nanoparticles efficiently inhibits skin inflammation in vivo. J Control Release 170: 51-63.

142.Zhongfa L, Chiu M, Wang J, Chen W, Yen W, et al. (2012) Enhancement of curcumin oral absorption and pharmacokinetics of curcuminoids and curcumin metabolites in mice. Cancer Chemother Pharmacol 69: 679-689.

143. Sasaki H, Sunagawa Y, Takahashi K, Imaizumi A, Fukuda H, et al. (2011) Innovative preparation of curcumin for improved oral bioavailability. Biol Pharm Bull 34: 660-665.

144. Yuan JM, Sun C, Butler LM (2011) Tea and cancer prevention: epidemiological studies. Pharmacol Res 64: 123-135.

145. Fujiki H, Suganuma M, Imai K, Nakachi K (2002) Green tea: cancer preventive beverage and/or drug. Cancer Lett 188: 9-13.

146. Nakachi K, Matsuyama S, Miyake S, Suganuma M, Imai K (2000) Preventive effects of drinking green tea on cancer and cardiovascular disease: epidemiological evidence for multiple targeting prevention. Biofactors 13: 49-54.

147. Fan Y, Yuan JM, Wang R, Gao YT, Yu MC (2008) Alcohol, tobacco, and diet in relation to esophageal cancer: the Shanghai Cohort Study. Nutr Cancer 60: 354-363.

148. Yuan JM, Ross RK, Wang XL, Gao YT, Henderson BE, et al. (1996) Morbidity and mortality in relation to cigarette smoking in Shanghai, China. A prospective male cohort study. JAMA 275: 1646-1650. 